13. Unified Vision, Unified Voice: Primary Care Speaks As One. Accessed Apr 15, 2021. https://www.newprimarycareparadigm.org/

14. Newton WP, Mitchell KB, Magill MK. The future of family medicine residency education: the specialty has spoken. Ann Fam Med. 2021; 19(2):185-187. 10.1370/afm.2677

\section{STFM LAUNCHES NEW PHASE OF INITIATIVE TO ADDRESS SHORTAGE OF COMMUNITY PRECEPTORS}

US MD-granting school enrollment grew 33\% between 2002-2003 and 2019-2020. Enrollment at DO-granting schools grew even faster, increasing the need for already scarce clinical training sites for students. ${ }^{1-2}$ According to a 2019 Association of American Medical Colleges survey, $84 \%$ of deans at MD-granting schools are concerned about the number of clinical training sites and $86 \%$ are concerned about the supply of qualified primary care preceptors. ${ }^{1}$

The struggle to obtain and retain high-quality clinical training sites is not new. Since late 2015, The Society of Teachers of Family Medicine (STFM) has been leading an interdisciplinary, interprofessional initiative to decrease the percentage of primary care clerkship directors who report difficulty finding clinical preceptor sites and increase the percentage of students completing clerkships at high-functioning sites.

Although the initiative has celebrated many successes, the increasing competition for clinical training sites, changes in difficulty replacing retired physician volunteers, and "changes in health system alignment impacting student placements" ${ }^{\prime \prime}$ means the need for innovative solutions is ongoing.

STFM has launched a new phase of the Preceptor Expansion Initiative, with broad dissemination of results and resources from Phase One. A key part of this new phase is Promoting Precepting - an AAFP Chapter Engagement Project. This includes:

- A presentation - New Ideas for Tackling the Preceptor Shortage in Your State - for chapter staff and leaders at the AAFP's Chapter Leadership Forum

- A virtual meeting for chapter executives from states that have tax incentives for preceptors to see if the incentives are making an impact

- A virtual panel presentation with and for chapter staff and leaders: The Preceptor Shortage: What's Worked in our State
- Precepting presentations for chapters for their virtual and in-person annual meetings

- Exhibits promoting precepting at chapter meetings

- A series of 1-page tips for chapters to share with preceptors in their publications and/or on their websites. These include:

- Incentives for precepting

- Precepting telemedicine visits

- Student documentation in the EHR

- Giving feedback

- Print and social media ads for chapter publications

Resources and more information is available at https://stfm.org/PreceptingResourcesForChapters.

\section{Update on Phase One}

The Preceptor Expansion Initiative launched in August 2016 with a Summit to identify the most significant reasons for the shortage of community preceptors and to shape the priorities, leadership, and investments needed to ensure the ongoing education of the primary care workforce.

The outcome of the Summit was an action plan that has been implemented over the past several years. Key successes include:

- A change in CMS documentation guidelines to allow students to document in the EMR without redocumentation by the preceptor

- Clerkship onboarding modules for students on how to write a high-quality note in the EMR, how to perform medication reconciliation, and motivational interviewing - A student onboarding passport that is shared with preceptors prior to rotations. It includes demographic information, personal learning objectives, a list of completed rotations, a list of procedural training, and verification of completion of online modules

- A guideline for program administrators or clinical coordinators to assist with community faculty appointments

- Awards for preceptors and precepting practices

- An ABFM Performance Improvement Activity where preceptors meet performance improvement requirements for continuing certification by precepting learners and implementing projects to improve their teaching skills

A project to pilot the resources was completed in December of 2020 and results are pending publication. The resources are available at https://stfm.org/ PreceptorExpansion.

The Preceptor Expansion Initiative is funded by the Society of Teachers of Family Medicine, the American Board of Family Medicine Foundation, and the Physician Assistant Education Association.

Mary Theobald, MBA, Chief of Strategy and Innovation, STFM 